Research Paper

\title{
Prediction of Gestational Diabetes Mellitus by Unconjugated Estriol Levels in Maternal Serum
}

\author{
Junguk Hur ${ }^{1}$, Eun-Hee Cho², Kwang-Hyun Baek ${ }^{3}$, and Kyung Ju Lee ${ }^{4,5 \bowtie ~}$ \\ 1. Department of Biomedical Sciences, University of North Dakota, Grand Forks, North Dakota, USA. \\ 2. Department of Internal Medicine, Kangwon National University, Chuncheon, Republic of Korea; \\ 3. Department of Biomedical Science, CHA University, Gyeonggi-Do, Republic of Korea; \\ 4. Integrative Medicine Center, College of Medicine, Korea University, Seoul, Republic of Korea; \\ 5. Department of Epidemiology and Medical informatics, Graduate School of Public Health, College of Medicine, Korea University, Seoul, Republic of Korea.
}

$\triangle$ Corresponding author: Kyung-Ju Lee, MD, PhD, Integrative Medicine Center, College of Medicine Korea University, Inchon-ro 73, Seongbuk-gu, Seoul, 02841, Republic of Korea. Tel: 82-2-920-6933; Fax: 82-2-920-6934; E-mail: drlkj52551@korea.ac.kr.

(C) Ivyspring International Publisher. This is an open access article distributed under the terms of the Creative Commons Attribution (CC BY-NC) license (https://creativecommons.org/licenses/by-nc/4.0/). See http://ivyspring.com/terms for full terms and conditions.

Received: 2016.08.23; Accepted: 2016.12.08; Published: 2017.02.07

\begin{abstract}
The aim of this study was to evaluate the association between maternal serum estriol levels, which are routinely measured in the first trimester of pregnancy, and adverse pregnancy outcomes including gestational diabetes. We performed a retrospective chart analysis of women who delivered between July 1, 2007, and December 31, 2009, at Kangnam CHA Medical Center in Seoul, Korea. Only patients with available estriol measurements during their pregnancies and complete follow-up data were included in the study. The effect of estriol on the incidence of adverse pregnancy outcomes was examined using multinomial logistic regression analysis with age and pre-pregnancy body mass index (BMI) as covariates. The total number of subjects was 1,553 , the mean age was $32.9 \pm 3.7$ years, and the mean pre-pregnancy BMI was $21.2 \pm 3.0 \mathrm{~kg} / \mathrm{m}^{2}$. Unconjugated estriol $>95^{\text {th }}$ percentile of the screened population or unconjugated estriol $\geq 2.0 \mathrm{MoM}$ (Multiple of the Median) was significantly associated with an increased risk for developing gestational diabetes mellitus (GDM), after adjusting for age and pre-pregnancy maternal weight. High levels of unconjugated estriol in the maternal serum during the early second trimester of pregnancy are a useful predictor of GDM development.
\end{abstract}

Key words: Estriol, pregnancy outcomes, gestational diabetes.

\section{Introduction}

Fetoplacental endocrine changes during pregnancy affect maternal and fetal outcomes [1, 2]. Maternal estrogen, progesterone, adiponectin, and leptin levels are related to body weight and insulin sensitivity [3-7]. In particular, estrogen and its receptor are known to be important regulators of body weight and insulin sensitivity [3]. Estriol (E3) is a weak estrogen agonist, but has potent antagonistic activity when present together with estradiol (E2) [8-10].

Pregnancy is characterized by weight gain [11] and a state of insulin resistance. Some studies have reported insulin sensitivities 50 to $70 \%$ lower in pregnant compared to non-pregnant women $[12,13]$, and this change contributes to the development of gestational diabetes mellitus (GDM). The currently available standard oral glucose tolerance test (OGTT) is only capable of diagnosing the physiological diabetogenic state late in pregnancy $[12,14-16]$, by which point it is too late to take preemptive actions to prevent diabetic complications. Many clinical researchers are interested in studying changes in routinely screened maternal biochemical markers [17-21] or gestational weight changes [22-25] in order to diagnose adverse pregnancy complications including GDM early.

Estrogens produced by the placenta exert normal endocrine effects during pregnancy, and we hypothesized that these hormones may be involved in the regulation of insulin sensitivity, and thus play a role in the development of GDM. One previous report has demonstrated that patients with HCG > 1.04 MoM 
(Multiple of the Median) and unconjugated E3 (uE3) $\leq$ $0.88 \mathrm{MoM}$ measured in a triple test were associated with GDM development [21]. Some studies found that low maternal uE3 levels in the second trimester were associated with fetal growth restriction [20], increased risk of pregnancy loss [19, 26], preterm birth [19] and decreases in birth weight for gestational age [27]. Another study showed that maternal serum E2 and E3 at delivery were significantly and positively correlated with birth weight [28].

The aim of this study was to evaluate the clinical utility of maternal serum uE3 level, a biochemical marker measured routinely in the early second trimester, to predict adverse pregnancy outcomes including gestational diabetes in a large cohort of Korean women with singleton pregnancies. We based our analysis on two models; 1 ) we used $\leq 5^{\text {th }}$ percentile or $\geq 95^{\text {th }}$ percentile cut-offs of serum marker raw values generated from our study population after adjusting for age and maternal weight, as well as 2) the generally accepted predefined MoM cut-off values, which are automatically programmed to adjust for age and gestational maternal weight.

\section{Materials and Methods}

\section{Study subjects}

This study used data obtained from pregnant women who delivered between July 1, 2007, and December 31, 2009, at Kangnam CHA Medical Center (Seoul, Korea). The present study protocol was reviewed and approved by the Institutional Review Board (IRB) of Kangnam CHA Medical Center (IRB No. KNC 10-025). Participants were excluded if they had a twin pregnancy, fetal anomaly, hypertensive disorder before pregnancy, preexisting diabetes, and missing pre-pregnancy or delivery weights. All participants underwent measurements of the first trimester biochemical marker PAPP-A, and the early second trimester biochemical biomarkers AFP, free beta-HCG, uE3, and inhibin A. Retrospective chart analyses of 1,553 women with complete follow-up data who delivered in our institution with available E3 measurements during their pregnancies were included in the study.

We defined abnormal levels of each maternal serum marker as $\leq 5^{\text {th }}$ percentile or $\geq 95^{\text {th }}$ percentile of the overall screened population, which were measured in weeks $16.4 \pm 0.7$ of gestation, and we compared those with MoM reference levels of each maternal serum marker.

\section{Adverse pregnancy outcomes}

Adverse pregnancy outcomes included (A) preterm birth (delivery at less than 37 weeks' gestation), (B) GDM ( $\geq 2$ positive results in a 3-hour 100g OGTT), (C) macrosomia (birth weight $\geq 4,000 \mathrm{~g}$ ), (D) large or small for gestational age (LGA or SGA; birth weight $>90^{\text {th }}$ or $<10^{\text {th }}$ percentiles), (E) primary cesarean section (P-CS; due to failure to progress, mal-presentation of the fetus, and past history of uterus operation, but excluding repetitive CSs), (F) low 1-min APGAR scores < 5, and (G) pregnancy-induced hypertension (PIH; systolic blood pressure $>140 \mathrm{mmHg}$ or diastolic blood pressure $>90$ mmHg after 20 weeks' gestation).

\section{Statistical Analysis}

Data were demonstrated using descriptive statistics as mean \pm standard deviation unless otherwise stated. The effect of E3 on the incidences of adverse outcomes was examined using multinomial logistic regression with age and pre-pregnancy maternal weight as covariates. The level of statistical significance was considered as $P$-value $<0.05$. For statistical analyses, $\mathrm{R}$ version 3.3 .0 (http://cran.rproject.org/) was used.

\section{Results}

Table 1 summarizes the clinical characteristics of the study cohort. The total number of subjects was 1,553 , the mean age was $32.9 \pm 3.7$ years, and the mean pre-pregnancy BMI was $21.2 \pm 3.0 \mathrm{~kg} / \mathrm{m}^{2}$. Approximately $59 \%$ of women were nulliparous and $17.5 \%$ of women had a family history of diabetes mellitus. The mean early second trimester biochemical biomarkers were investigated at $16.4 \pm 0.7$ weeks of gestation and mean birth weight was 3,282.5 $\pm 435.7 \mathrm{~g}$.

Table 1. Clinical characteristics of the study subjects.

\begin{tabular}{ll}
\hline Characteristic & Mean \pm SD or number \\
\hline Number of subjects $(\mathrm{n})$ & 1,553 \\
Maternal age (years) & $32.9 \pm 3.7$ \\
Parity & \\
0 & $914(58.9 \%)$ \\
$\geq 1$ & $639(41.1 \%)$ \\
History of hypertension $(\mathrm{n}, \%)$ & $9(0.6 \%)$ \\
Family history of DM $(\mathrm{n}, \%)$ & $272(17.5 \%)$ \\
Family history of hypertension $(\mathrm{n}, \%)$ & $314(20.2 \%)$ \\
Pre-pregnancy BMI $\left(\mathrm{kg} / \mathrm{m}^{2}\right)$ & $21.2 \pm 3.0$ \\
Gestational age at (weeks) & \\
First trimester biochemistry markers & $11.9 \pm 0.7$ \\
Early second trimester biochemistry markers & $16.4 \pm 0.7$ \\
OGTT & $27.9 \pm 1.7$ \\
Delivery & $39.1 \pm 1.4$ \\
Birth weight (g) & $3,282.5 \pm 435.7$ \\
\hline DM: Diabetes Mellitus; BMI: Body Mass Index; OGTT: Oral Clucose Tolerance Test
\end{tabular}

Table 2 shows the odds ratios (ORs) for developing adverse outcomes for serum estriol based on the percentile cut-off of raw values generated from our study population after adjusting for age and 
maternal pre-pregnancy weight. $\mathrm{uE} 3>95^{\text {th }}$ percentile of the overall screened population was associated with an increased risk for GDM (OR 2.05, $P=4.94 \mathrm{E}-05)$, primary cesarean section (OR 4.06, $P=0.12$ ), and $\mathrm{PIH}$ $(\mathrm{OR}=3.78, \quad P=0.00047)$ after controlling for pre-pregnancy maternal weight and age.

In Table 3, we measured the OR for developing adverse pregnancy outcomes for serum uE3 using predefined MoM cut-off values. A uE3 value $\geq 2.0$ MoM was associated with GDM (OR=4.11, $P=0.0005)$, but a uE3 value $\leq 0.5 \mathrm{MoM}$ was not associated with any adverse pregnancy outcomes.

As shown in Tables 2 and 3, uE3 $>95^{\text {th }}$ percentile or $\geq 2.0 \mathrm{MoM}$ was associated with an increased risk for GDM irrespective of any modeling. Compared to the predefined MoM cut-off values generated automatically by computer software programs, the other modeling using percentile cut-off of raw values generated from our study population showed a stronger association between maternal serum uE3 and adverse pregnancy outcomes such as primary cesarean section and PIH, but not GDM.

Tables 4 and 5 list multinomial logistic regression analyses and show that $\mathrm{uE3} \geq 95^{\text {th }}$ percentile or $\geq 2.0 \mathrm{MoM}$ was associated with the development of gestational diabetes irrespective of any covariate adjustment.

Table 2. The odds ratios for developing adverse outcomes for each serum marker using raw values adjusted for age and maternal weight.

\begin{tabular}{|c|c|c|c|c|c|c|c|c|c|}
\hline & & P-CS & GDM & LGA & Low APGAR & Macrosomia & PIH & Preterm & SGA \\
\hline Groups & Actual cutoff & $999(12.9 \%)$ & $202(63.9 \%)$ & $80(4.4 \%)$ & $45(5.3 \%)$ & $69(5.1 \%)$ & $65(4.2 \%)$ & $80(5.1 \%)$ & $83(2.9 \%)$ \\
\hline $\begin{array}{l}\text { AFP lower } \\
\text { ( } \leq 5^{\text {th }} \text { percentile) }\end{array}$ & $23.44 \mathrm{ng} / \mathrm{mL}$ & $1.53(0.91-2.57)$ & $1.27(0.69-2.32)$ & $1.42(0.64-3.14)$ & $2.89(1.14-7.32)$ * & $1.71(0.77-3.82)$ & $1.47(0.60-3.59)$ & $1.08(0.41-2.82)$ & $1.71(0.66-4.47)$ \\
\hline $\begin{array}{l}\text { AFP upper } \\
\left(\geq 95^{\text {th }} \text { percentile) }\right.\end{array}$ & $73.11 \mathrm{ng} / \mathrm{mL}$ & $1.15(0.70-1.87)$ & $0.74(0.33-1.65)$ & $0.62(0.15-2.62)$ & $0.47(0.06-3.51)$ & $0.75(0.18-3.18)$ & $2.42(0.92-6.37)$ & $0.79(0.24-2.58)$ & $1.34(0.56-3.22)$ \\
\hline $\begin{array}{l}\text { E3 lower } \\
\left(\leq 5^{\text {th }} \text { percentile) }\right.\end{array}$ & $0.60 \mathrm{ng} / \mathrm{mL}$ & $1.44(0.87-2.40)$ & $1.13(0.58-2.19)$ & $1.11(0.42-2.90)$ & $2.43(0.92-6.38)$ & $1.31(0.50-3.43)$ & $1.34(0.46-3.89)$ & $1.57(0.66-3.77)$ & $0.83(0.25-2.71)$ \\
\hline $\begin{array}{l}\text { E3 upper } \\
\left(\geq 95^{\text {th }} \text { percentile) }\right.\end{array}$ & $12.60 \mathrm{ng} / \mathrm{mL}$ & $4.06(2.06-8.00)$ * & $2.05(1.17-3.57)^{*}$ & $0.89(0.31-2.58)$ & $0.46(0.06-3.37)$ & $0.76(0.23-2.56)$ & $3.78(1.79-7.97)$ * & $1.04(0.37-2.92)$ & $1.67(0.70-3.98)$ \\
\hline $\begin{array}{l}\text { HCG lower } \\
\left(\leq 5^{\text {th }} \text { percentile) }\right.\end{array}$ & $15.58 \mathrm{IU} / \mathrm{mL}$ & $1.00(0.62-1.61)$ & $0.61(0.28-1.36)$ & $0.33(0.08-1.40)$ & $0.39(0.05-2.85)$ & $0.39(0.09-1.67)$ & $0.52(0.12-2.21)$ & $0.68(0.21-2.22)$ & $0.56(0.14-2.36)$ \\
\hline $\begin{array}{l}\text { HCG upper } \\
\left(\geq 95^{\text {th }} \text { percentile) }\right.\end{array}$ & $125.90 \mathrm{IU} / \mathrm{mL}$ & $3.32(1.77-6.24) *$ & $2.58(1.51-4.42)^{*}$ & $0.53(0.13-2.20)$ & 0.00 (0.00 - Inf) & $0.63(0.15-2.64)$ & $3.55(1.59-7.90)$ * & $1.04(0.37-2.93)$ & $2.09(0.97-4.53)$ \\
\hline $\begin{array}{l}\text { Inhibin lower } \\
\left(\leq 5^{\text {th }} \text { percentile) }\right.\end{array}$ & $92.40 \mathrm{pg} / \mathrm{mL}$ & $1.31(0.74-2.29)$ & $0.85(0.39-1.84)$ & $0.91(0.31-2.68)$ & $0.47(0.06-3.54)$ & 0.00 (0.00 - Inf $)$ & $0.64(0.15-2.77)$ & $1.23(0.43-3.52)$ & $2.20(0.84-5.80)$ \\
\hline $\begin{array}{l}\text { Inhibin upper } \\
\left(\geq 95^{\text {th }} \text { percentile) }\right.\end{array}$ & $397.10 \mathrm{pg} / \mathrm{mL}$ & $1.37(0.79-2.38)$ & $0.51(0.18-1.43)$ & $0.00(0.00-$ Inf $)$ & 0.00 (0.00 - Inf) & 0.00 (0.00 - Inf $)$ & $1.81(0.53-6.20)$ & $0.28(0.04-2.07)$ & $2.26(0.96-5.29)$ \\
\hline $\begin{array}{l}\text { PAPPA lower } \\
\left(\leq 5^{\text {th }} \text { percentile) }\right.\end{array}$ & $1.02 \mathrm{mIU} / \mathrm{mL}$ & $1.25(0.69-2.25)$ & $2.10(1.03-4.26)^{*}$ & $0.24(0.03-1.79)$ & $0.49(0.06-3.68)$ & $0.55(0.13-2.41)$ & $1.57(0.44-5.57)$ & $1.96(0.73-5.23)$ & $1.21(0.36-4.08)$ \\
\hline $\begin{array}{l}\text { PAPPA upper } \\
\left(\geq 95^{\text {th }} \text { percentile) }\right.\end{array}$ & $10.09 \mathrm{mIU} / \mathrm{mL}$ & $4.52(1.89-10.82)$ * & $2.08(0.97-4.45)$ & $0.52(0.07-3.94)$ & $0.63(0.08-4.78)$ & $0.00(0.00-$ Inf $)$ & $3.50(0.97-12.55)$ & $0.96(0.22-4.12)$ & $2.63(1.05-6.57)^{*}$ \\
\hline
\end{tabular}

*: P<0.05. P-CS: primary caesarian section, GDM: gestational diabetes mellitus, LGA: large for gestational age, SGA: small for gestational age, PIH: pregnancy-induced hypertension, PAPPA: pregnancy-associated plasma protein A, AFP: alpha-fetoprotein, HCG: human chorionic gonadotropin, E3: estriol, Inf: infinity.

Table 3. The odds ratios for developing adverse outcomes for each serum marker using MoM values with predefined cutoffs for upper and lower limits (no co-variates).

\begin{tabular}{|c|c|c|c|c|c|c|c|c|}
\hline & P-CS & GDM & LGA & $\begin{array}{l}\text { Low }_{-} \\
\text {APGAR }\end{array}$ & Macrosomia & PIH & Preterm & SGA \\
\hline Groups & $999(12.9 \%)$ & $202(63.9 \%)$ & $80(4.4 \%)$ & $45(5.3 \%)$ & $69(5.1 \%)$ & $65(4.2 \%)$ & $80(5.1 \%)$ & $83(2.9 \%)$ \\
\hline AFP_MOM Lower $(\leq 0.25)$ & 161119.37 (0.00 - Inf) & $0.00(0.00-\mathrm{Inf})$ & $0.00(0.00-\mathrm{Inf})$ & $0.00(0.00-$ Inf $)$ & $0.00(0.00-$ Inf $)$ & $0.00(0.00-$ Inf $)$ & $0.00(0.00-$ Inf $)$ & $0.00(0.00-$ Inf $)$ \\
\hline AFP_MOM Upper $(\geq 2.0)$ & $0.82(0.40-1.68)$ & $0.69(0.21-2.29)$ & $0.59(0.08-4.38)$ & $0.00(0.00-$ Inf $)$ & $0.00(0.00-$ Inf $)$ & $3.42(1.16-10.07)$ \$ & $0.61(0.08-4.50)$ & $1.89(0.56-6.34)$ \\
\hline E3_MOM Lower $(\leq 0.5)$ & $0.95(0.41-2.18)$ & $1.00(0.29-3.38)$ & $0.82(0.11-6.12)$ & $3.24(0.74-14.24)$ & $0.96(0.13-7.23)$ & $1.04(0.14-7.87)$ & $0.84(0.11-6.30)$ & $0.78(0.10-5.87)$ \\
\hline E3_MOM Upper $(\geq 2.0)$ & $1.62(0.68-3.86)$ & $4.11(1.85-9.11) \$$ & $2.35(0.69-7.96)$ & $0.00(0.00-$ Inf $)$ & $2.76(0.81-9.41)$ & $3.00(0.88-10.25)$ & $2.41(0.71-8.19)$ & $0.69(0.09-5.17)$ \\
\hline HCG_MOM Lower $(\leq 0.5)$ & $1.23(0.81-1.86)$ & $0.80(0.43-1.48)$ & $0.66(0.24-1.85)$ & $0.29(0.04-2.12)$ & $0.77(0.27-2.15)$ & $0.44(0.10-1.81)$ & $1.06(0.45-2.51)$ & $0.88(0.35-2.22)$ \\
\hline HCG_MOM Upper $(\geq 2.0)$ & $1.48(1.00-2.21)$ & $0.92(0.53-1.60)$ & $0.86(0.37-2.02)$ & $0.50(0.12-2.08)$ & $0.65(0.23-1.82)$ & $1.77(0.85-3.67)$ & $0.74(0.29-1.88)$ & $1.38(0.67-2.84)$ \\
\hline Inhibin_MOM Lower $(\leq 0.5)$ & $1.38(0.73-2.61)$ & $0.65(0.23-1.85)$ & $1.81(0.63-5.23)$ & $0.68(0.09-5.05)$ & $0.00(0.00-\mathrm{Inf})$ & $1.90(0.56-6.39)$ & $1.85(0.64-5.34)$ & $0.90(0.21-3.81)$ \\
\hline Inhibin_MOM Upper $(\geq 2.0)$ & $1.28(0.86-1.92)$ & $0.92(0.51-1.64)$ & $1.01(0.43-2.40)$ & $0.26(0.04-1.90)$ & $0.94(0.37-2.41)$ & $1.19(0.46-3.09)$ & $0.85(0.33-2.17)$ & $1.43(0.66-3.07)$ \\
\hline PAPPA_MOM Lower $(\leq 0.4)$ & $1.24(0.82-1.89)$ & $1.88(1.14-3.10) \$$ & $0.62(0.22-1.74)$ & $0.80(0.24-2.67)$ & $0.72(0.25-2.05)$ & $3.40(1.64-7.03) \$$ & $1.31(0.60-2.84)$ & $1.43(0.66-3.12)$ \\
\hline PAPPA_MOM Upper $(\geq 2.5)$ & $0.92(0.62-1.38)$ & $0.78(0.41-1.51)$ & $0.77(0.30-1.98)$ & $0.26(0.04-1.92)$ & $0.53(0.16-1.74)$ & $0.56(0.13-2.39)$ & $0.15(0.02-1.11)$ & $1.42(0.65-3.09)$ \\
\hline
\end{tabular}

\$: P<0.05; P-CS: primary caesarian section; GDM: gestational diabetes mellitus; LGA: large for gestational age; SGA: small for gestational age; PIH: pregnancy-induced

hypertension.

Table 4. Multinomial logistic regression analysis of developing gestational diabetes using uE3 percentiles.

\begin{tabular}{|c|c|c|c|c|c|c|}
\hline & \multicolumn{2}{|c|}{$\begin{array}{l}\text { Model } 1 \\
\text { (Adjusted for pre-pregnancy maternal weight and age) }\end{array}$} & \multicolumn{2}{|c|}{$\begin{array}{l}\text { Model } 2 \\
\text { (Adjusted for pre-pregnancy maternal weight) }\end{array}$} & \multicolumn{2}{|l|}{$\begin{array}{l}\text { Model } 3 \\
\text { (No adjustment) }\end{array}$} \\
\hline & OR $(95 \% \mathrm{CI})$ & $\mathbf{P}$ & OR $(95 \% \mathrm{CI})$ & $\mathbf{P}$ & OR $(95 \% \mathrm{CI})$ & $\mathbf{P}$ \\
\hline E3 upper ( $\geq 95^{\text {th }}$ percentile) & $2.05(1.17-3.57)$ & 0.012 & $2.04(1.17-3.55)$ & 0.012 & $2.13(1.23-3.69)$ & 0.007 \\
\hline E3 lower ( $\leq 5^{\text {th }}$ percentile) & $1.13(0.58-2.19)$ & 0.727 & $1.13(0.58-2.20)$ & 0.713 & $1.16(0.60-2.25)$ & 0.650 \\
\hline
\end{tabular}


Table 5. Multinomial logistic regression analysis of developing gestational diabetes using predefined MoM cutoffs.

\begin{tabular}{|c|c|c|c|c|c|c|}
\hline & \multicolumn{2}{|c|}{$\begin{array}{l}\text { Model } 1 \\
\text { (Adjusted for pre-pregnancy maternal weight and age) }\end{array}$} & \multicolumn{2}{|c|}{$\begin{array}{l}\text { Model } 2 \\
\text { (Adjusted for pre-pregnancy maternal weight) }\end{array}$} & \multicolumn{2}{|l|}{$\begin{array}{l}\text { Model } 3 \\
\text { (No adjustment) }\end{array}$} \\
\hline & OR $(95 \% \mathrm{CI})$ & $\mathbf{P}$ & OR $(95 \% \mathrm{CI})$ & $\mathbf{P}$ & OR $(95 \% \mathrm{CI})$ & $\mathbf{P}$ \\
\hline E3_MOM Upper $(\geq 2.0)$ & $3.67(1.63-8.27)$ & 0.002 & $3.62(1.61-8.13)$ & 0.002 & $4.11(1.85-9.11)$ & 0.000 \\
\hline E3_MOM Lower $(\leq 0.5)$ & $0.90(0.26-3.08)$ & 0.868 & $0.90(0.26-3.06)$ & 0.863 & $1.00(0.29-3.38)$ & 0.998 \\
\hline
\end{tabular}

Odd ratios (ORs) and 95\% confidence intervals (CIs) from the logistic regression analysis are given in the table.

\section{Discussion}

During the early stages of pregnancy, progesterone and $17 \beta$-estradiol are secreted by the corpus luteum until the placenta develops and is able to take over the role of hormone synthesis for the remainder of the pregnancy [29]. The levels of estrogen and progesterone continue to rise throughout pregnancy [2].

Maternal hormones are regulated by the maternal pituitary gland and the placenta, and play a key role in the physiologic development of maternal insulin resistance [30]. To compensate for these physiological changes, maternal insulin resistance is counteracted by an upregulation of insulin production via the proliferation of $\beta$-cells, the stimulation of insulin gene expression, and glucose dependent insulin secretion throughout gestation, thus allowing the blood glucose concentration to remain within the physiological range [30]. If this $\beta$-cell response fails to adapt to the higher insulin demands of pregnancy, GDM may develop. One hypothesis is that a disruption of the $\beta$-cell response to maternal hormones contributes to the development of GDM. The role of the maternal hormone estrogen in this pregnancy adaptation process is largely unknown. However, it has been shown that E2 acts directly on $\beta$-cells to promote insulin biosynthesis and $\beta$-cell survival [29]. Estrogen receptors are expressed in the $\beta$-cells of the pancreatic islets and $17 \beta$-estradiol has been shown to enhance insulin biosynthesis and glucose-dependent insulin secretion $[29,31,32]$.

Interestingly, E3 has a weak estrogenic effect when administered to ovariectomized animals, but acts as an antiestrogen when administered in combination with E2 [8]. E3 inhibits the positive cooperative binding of E2 to the estrogen receptor [9]. The antagonistic properties of E3 were correlated with its capacity to abolish the positive cooperative binding interaction between E2 and its receptor, and 50\% inhibition of $\left[{ }^{3} \mathrm{H}\right]$-estradiol binding by $\mathrm{E} 3$ was sufficient to entirely abolish the positive cooperative interaction of E2 with the estrogen receptor [9, 10]. In vitro, E3 has been shown to induce insulin resistance in 3T3-L1 adipocytes by reducing insulin stimulated glucose transport [33]. E2 and E3 production increases throughout normal pregnancy, and serum E3 levels are much higher than E2 levels [2]. The onset of GDM in humans occurs during the second trimester of pregnancy, at a time when progesterone, E2 and E3 levels increase [2, 29].

Our data showed for the first time that an early second trimester E3 $>95^{\text {th }}$ percentile of raw values generated from our study population or $\geq$ predefined 2.0 MoM is associated with an increased risk for developing GDM. It is possible that very high maternal serum levels of E3 in early pregnancy inhibit the interaction of E2 with its receptor, thus promoting insulin resistance and the development of GDM.

On the other hand, a previous study in humans demonstrated that low uE3 levels in the second trimester were associated with fetal growth restriction [20] and a decrease in birth weight for gestational age [27]. Maternal serum E2 and E3 at delivery were significantly and positively correlated with birth weight [28]. However, our study showed no association between maternal serum $\mathrm{uE3} \leq 5^{\text {th }}$ percentile or $\mathrm{uE3} \leq 0.5 \mathrm{MoM}$ and adverse pregnancy outcomes including macrosomia, and SGA infants.

MoM is a measure of how far an individual test result deviates from the median, and is commonly used to report the results of prenatal screening tests, particularly where results of the individual tests are highly variable [34]. Medians used to calculate the MoM must be representative of the population studied. Currently, MoM levels are determined by geographic regions, ethnic and analytic variation, and maternal age and weight. However, no reference levels representative of our geographical region have been determined from the prenatal screening marker results of normal pregnant women without adverse pregnancy outcomes. Therefore, we utilized $\leq 5^{\text {th }}$ percentile or $\geq 95^{\text {th }}$ percentile cut-offs of raw values generated from our study population for each serum marker adjusted for maternal age and maternal weight. Compared to the predefined MoM cut-off values generated automatically by computer software programs, our method showed wider association between maternal serum uE3 and adverse pregnancy outcomes including primary cesarean section, GDM, and PIH. Our findings suggest that percentile cut offs may be more clinically relevant for predicting adverse pregnancy outcomes compared with the currently available MoM values in Koreans. The strengths of our study include accurate and complete maternal 
serum uE3 data and comprehensive general pregnancy outcome data, including APGAR scores. This study is limited by its retrospective design and the relatively small sample size.

In conclusion, maternal serum $\mathrm{uE3}>95^{\text {th }}$ percentile of the overall screened population or $\mathrm{uE} 3 \geq$ 2.0 MoM was associated with an increased risk of developing GDM after controlling for age and pre-pregnancy maternal weight.

\section{Acknowledgments}

The authors thank the participants in the study cohort and the staff at Kangnam CHA Hospital. This study was funded by the Korea Ministry of Environment (MOE) as "the Environmental Health Action Program (2016001360008)".

\section{Competing Interests}

The authors have declared that no competing interest exists.

\section{References}

1. Kuijper EA, Ket JC, Caanen MR, Lambalk CB. Reproductive hormone concentrations in pregnancy and neonates: a systematic review. Reproductive biomedicine online. 2013; 27: 33-63.

2. Smith R, Smith JI, Shen X, Engel PJ, Bowman ME, McGrath SA, et al. Patterns of plasma corticotropin-releasing hormone, progesterone, estradiol, and estriol change and the onset of human labor. The Journal of clinical endocrinology and metabolism. 2009; 94: 2066-74.

3. Meyer MR, Clegg DJ, Prossnitz ER, Barton M. Obesity, insulin resistance and diabetes: sex differences and role of oestrogen receptors. Acta physiologica (Oxford, England). 2011; 203: 259-69.

4. Dzaja A, Wehrle R, Lancel M, Pollmacher T. Elevated estradiol plasma levels in women with restless legs during pregnancy. Sleep. 2009; 32: 169-74.

5. Gol M, Altunyurt S, Cimrin D, Guclu S, Bagci M, Demir N. Different maternal serum hCG levels in pregnant women with female and male fetuses: does fetal hypophyseal--adrenal--gonadal axis play a role? Journal of perinatal medicine. 2004; 32: 342-5.

6. Lagiou P, Tamimi R, Mucci LA, Trichopoulos D, Adami HO, Hsieh CC. Nausea and vomiting in pregnancy in relation to prolactin, estrogens, and progesterone: a prospective study. Obstetrics and gynecology. 2003; 101: 639-44.

7. Williams MA, Qiu C, Muy-Rivera M, Vadachkoria S, Song T, Luthy DA. Plasma adiponectin concentrations in early pregnancy and subsequent risk of gestational diabetes mellitus. J Clin Endocrinol Metab. 2004; 89: 2306-11.

8. Melamed M, Castano E, Notides AC, Sasson S. Molecular and kinetic basis for the mixed agonist/antagonist activity of estriol. Molecular endocrinology (Baltimore, Md). 1997; 11: 1868-78.

9. Sasson S, Notides AC. Estriol and estrone interaction with the estrogen receptor. II. Estriol and estrone-induced inhibition of the cooperative binding of $[3 \mathrm{H}]$ estradiol to the estrogen receptor. The Journal of biological chemistry. 1983; 258: 8118-22.

10. Sasson S, Notides AC. The estriol-induced inhibition of the estrogen receptor's positive cooperativity. Journal of steroid biochemistry. 1984; 20: 1021-6.

11. HUGO Gene Nomenclature Committee.

12. Catalano PM, Tyzbir ED, Roman NM, Amini SB, Sims EA. Longitudinal changes in insulin release and insulin resistance in nonobese pregnant women. American journal of obstetrics and gynecology. 1991; 165: 1667-72.

13. Butte NF. Carbohydrate and lipid metabolism in pregnancy: normal compared with gestational diabetes mellitus. The American journal of clinical nutrition. 2000; 71: 1256S-61S

14. D'Ippolito S, Tersigni C, Scambia G, Di Simone N. Adipokines, an adipose tissue and placental product with biological functions during pregnancy. BioFactors (Oxford, England). 2012; 38: 14-23.

15. Lacroix M, Kina E, Hivert MF. Maternal/fetal determinants of insulin resistance in women during pregnancy and in offspring over life. Current diabetes reports. 2013; 13: 238-44

16. Kuhl C. Insulin secretion and insulin resistance in pregnancy and GDM. Implications for diagnosis and management. Diabetes. 1991; 40 Suppl 2: 18-24.

17. Baschat AA, Magder LS, Doyle LE, Atlas RO, Jenkins CB, Blitzer MG. Prediction of preeclampsia utilizing the first trimester screening examination. American journal of obstetrics and gynecology. 2014.
18. Shiefa S, Amargandhi M, Bhupendra J, Moulali S, Kristine T. First Trimester Maternal Serum Screening Using Biochemical Markers PAPP-A and Free beta-hCG for Down Syndrome, Patau Syndrome and Edward Syndrome. Indian journal of clinical biochemistry : IJCB. 2013; 28: 3-12.

19. Huang T, Hoffman B, Meschino W, Kingdom J, Okun N. Prediction of adverse pregnancy outcomes by combinations of first and second trimester biochemistry markers used in the routine prenatal screening of Down syndrome. Prenatal diagnosis. 2010; 30: 471-7.

20. Kim SY, Kim SK, Lee JS, Kim IK, Lee K. The prediction of adverse pregnancy outcome using low unconjugated estriol in the second trimester of pregnancy without risk of Down's syndrome. Yonsei medical journal. 2000; 41: 226-9.

21. Sayin NC, Canda MT, Ahmet N, Arda S, Sut N, Varol FG. The association of triple-marker test results with adverse pregnancy outcomes in low-risk pregnancies with healthy newborns. Archives of gynecology and obstetrics. 2008; 277: 47-53.

22. Cho EH, Hur J, Lee KJ. Early Gestational Weight Gain Rate and Adverse Pregnancy Outcomes in Korean Women. PLoS One. 2015; 10: e0140376.

23. Carreno CA, Clifton RG, Hauth JC, Myatt L, Roberts JM, Spong CY, et al. Excessive early gestational weight gain and risk of gestational diabetes mellitus in nulliparous women. Obstet Gynecol. 2012; 119: 1227-33.

24. Hedderson MM, Gunderson EP, Ferrara A. Gestational weight gain and risk of gestational diabetes mellitus. Obstetrics and gynecology. 2010; 115: 597-604.

25. Macdonald-Wallis C, Tilling K, Fraser A, Nelson SM, Lawlor DA. Gestational weight gain as a risk factor for hypertensive disorders of pregnancy. American journal of obstetrics and gynecology. 2013; 209: 327.e1-17.

26. Santolaya-Forgas J, Jessup J, Burd LI, Prins GS, Burton BK. Pregnancy outcome in women with low midtrimester maternal serum unconjugated estriol. The Journal of reproductive medicine. 1996; 41: 87-90.

27. Talge NM, Holzman C, Senagore PK, Klebanoff M, Fisher R. Biological indicators of the in-utero environment and their association with birth weight for gestational age. Journal of developmental origins of health and disease. 2011; 2: 280-90.

28. Nagata C, Iwasa S, Shiraki M, Shimizu H. Estrogen and alpha-fetoprotein levels in maternal and umbilical cord blood samples in relation to birth weight. Cancer epidemiology, biomarkers \& prevention : a publication of the American Association for Cancer Research, cosponsored by the American Society of Preventive Oncology. 2006; 15: 1469-72.

29. Nadal A, Alonso-Magdalena P, Soriano S, Ropero AB, Quesada I. The role of oestrogens in the adaptation of islets to insulin resistance. The Journal of physiology. 2009; 587: 5031-7.

30. Freemark M. Regulation of maternal metabolism by pituitary and placental hormones: roles in fetal development and metabolic programming. Hormone research. 2006; 65 Suppl 3: 41-9.

31. Alonso-Magdalena P, Morimoto S, Ripoll C, Fuentes E, Nadal A. The estrogenic effect of bisphenol A disrupts pancreatic beta-cell function in vivo and induces insulin resistance. Environmental health perspectives. 2006; 114: 106-12.

32. Nadal A, Rovira JM, Laribi O, Leon-quinto T, Andreu E, Ripoll C, et al. Rapid insulinotropic effect of 17 beta-estradiol via a plasma membrane receptor. FASEB journal : official publication of the Federation of American Societies for Experimental Biology. 1998; 12: 1341-8.

33. Collison M, Campbell IW, Salt IP, Dominiczak AF, Connell JM, Lyall H, et al. Sex hormones induce insulin resistance in 3T3-L1 adipocytes by reducing cellular content of IRS proteins. Diabetologia. 2000; 43: 1374-80.

34. Bishop JC, Dunstan FD, Nix BJ, Reynolds TM, Swift A. All MoMs are not equal: some statistical properties associated with reporting results in the form of multiples of the median. American journal of human genetics. 1993; 52: $425-30$ 